\title{
Smoking patterns, knowledge of tobacco-related health effects, and desires to quit among 14- to 17-year-old boarding school pupils in Denmark, 1987-90
}

\author{
Erik J Jensen, Erik Overgaard
}

\begin{abstract}
Objectives - To estimate the prevalence of regular smokers and the trend in smoking prevalence over a 3-year period among Danish boarding school pupils aged 14-17 years. To evaluate the influence of sex and age on smoking status, students' knowledge of smoking-induced health hazards, and desires to stop smoking.
\end{abstract}

Design-Two independent crossout with an interval of three years (1986/87 and $1989 / 90)$. The $1986 / 87$ study was partly retrospective.

Subjects - A representative sample participated including 557 pupils in 1986/87 and 622 pupils in $1989 / 90$.

Main outcome measures - Prevalence of regular cigarette smoking, daily cigarette consumption, knowledge of health effects of smoking, and desires to quit.

Results-In 1986/87 the proportion of smokers $(p<0.0001)$ and daily cigarette consumption $(p<0.0001)$ increased after transition to boarding school. The percentage of regular smokers in $1986 / 87$ was $59.9 \%$ compared to $49.1 \%$ in $1989 / 90$ ( $p<$ 0.005 ), but the average daily cigarette consumption was higher in 1989/90 compared with $1986 / 87$ (p $<0.01)$. Knowledge of tobacco as a health hazard was unsatisfactory and similar for boys and girls, although girls were more aware than boys that smoking is a health threat. Most of the smoking pupils wanted to quit.

Conclusions-Smoking is highly prevalent among boarding school pupils. More information concerning the health hazards of smoking need to be provided to these students. Better identification of groups with high smoking prevalences are recommended in order to strengthen anti-smoking measures.

(Tobacco Control 1993; 2: 296-9) University Hospital, Aarhus, Denmark EJ Jensen

E Overgaard

Correspondence to: Dr Erik Juel Jensen, Department of Respiratory Diseases, University Hospital, Noerrebrogade, DK-8000 Aarhus C, Denmark

Introduction

Smoking is often the cause of disability and premature death. ${ }^{1}$ Smoking usually starts at a young age and it is important to establish sectional questionnaire surveys carried

efficient interventions against smoking at this level.

In Denmark children attend school for at least 9 years. From the seventh grade on, some $16000(10 \%)$ pupils attend a boarding school. The vast majority of 14- to 17-year-olds stay in the ordinary local public school and experience no major social changes before the age of 17 . In contrast, boarding school pupils leave their homes and return home only at weekends and holidays.

The percentage of smokers in ordinary public schools has decreased due to extensive anti-smoking campaigns, and is now less than $20 \% \cdot{ }^{2-4}$ The smoking behaviour of boarding school pupils is unknown and may differ from that of public school pupils because their social surroundings have changed and because they may differ from public school pupils in other ways.

We investigated the smoking behaviour of boarding school pupils and the influence of sex, age, and social background variables. Knowledge of smoking-related diseases and smokers' desires to quit were also evaluated. The prevalence of smokers was very high and was re-investigated after 3 years. Other analyses of data from this study were published previously. ${ }^{5}$

\section{Population and methods}

METHODS

This questionnaire survey was performed in $1986 / 87$ (study 1) and in 1989/90 (study 2). Study 1 collected information from students about their cigarette consumption before school transition ( $\mathrm{T} 1$ ) and their consumption at the time of the survey (T2). In study 2 the participants gave information about their current smoking behaviour (T3). Both surveys took place about 4 months after a new school year had started and after the pupils had been at the schools for 4 to 16 months. The same schools participated in studies 1 and 2 but the study populations were different as most pupils attend the schools for only two years and studies 1 and 2 were performed three years apart.
The questionnaires were filled out during class hours after explanation by the thoroughly informed teacher, who helped the pupils with questions that were not clearly understood. 
Participation was voluntary and anonymous. Anonymity was maintained by sealing the questionnaires in envelopes and considering sealed envelopes only.

To evaluate possible drop-out bias and to assess the validity of the information given by the pupils, a repeat questionnaire survey about current cigarette consumption was carried out 2 months after study 2 and included all pupils in three schools randomly chosen among the nine schools that had participated.

\section{POPULATION}

The country was partitioned into three main regions and in each of these regions three schools were chosen by lot. The numbers of students included in studies 1 and 2 (with the total number of pupils in the schools in parentheses) were $557(700)$ and 622 (720), respectively. The pupils' mean age (SD) in study 1 was 15.8 (1.9) years and in study 2 it was 15.6 (1.9) years. The numbers of boys and girls were about equal within each study. Because of absence from school or incomplete filling out of questionnaires, $20.4 \%$ of students in study 1 and $13.6 \%$ of students in study 2 were excluded.

\section{QUESTIONNAIRES}

The pupils were asked if they had tried to smoke, if they smoked sometimes but not regularly, if they regularly smoked but not daily, or if they smoked daily, and how many cigarettes they smoked per day and per week. Pupils stating regular and/or daily cigarette use and reporting daily or weekly cigarette consumption were regarded as smokers. All others were considered non-smokers.

The pupils' knowledge of the health hazards of tobacco smoking was elucidated in study 1 through questions such as whether they believed that cough was a sign of damage to the lungs; that smoking could cause lung cancer, other lung diseases, cardiovascular diseases, and general health damage; and whether each of these conditions could be dangerous. The responses were measured on a four-point scale: "yes", "maybe", "do not know", and "no".

Questions were asked in study 2 about desire to quit and reasons for desiring to quit (health hazard, costs, consideration of others, better fitness, and better appearance). Response choices were: "very much", "to some extent", "maybe", and "no".

Finally, students were queried about several social background variables including number of adults at home, parents' marital status and occupation, and the smoking status of parents and siblings.

ETHICS

The study was approved by the ethics committee of Aarhus County, Denmark.

\section{STATISTICS}

The BMDP-statistic package was employed in all analyses. ${ }^{6}$ Two-sided $95 \%$ confidence limits were employed. A p-value less than 0.05 was considered statistically significant and a pvalue between 0.05 and 0.10 was considered to represent a trend.

\section{Results}

SMOKING BEHAVIOUR BEFORE AND AFTER

SCHOOL TRANSITION (STUDY 1)

The percentage of regular smokers within each school was generally high and ranged from $45.3 \%$ to $79.0 \%$ at $\mathrm{T} 2$.

Table 1 gives the percentage of pupils who were regular smokers and the daily cigarette consumption before school transition (T1), and four months after (at the time of the investigation) (T2). The percentage of smokers increased from $\mathrm{T} 1$ to $\mathrm{T} 2\left(\chi^{2}=10.5 ; \mathrm{df}=1\right.$; $\mathrm{p}<0.001)$. Fifty-six pupils started to smoke daily at the boarding school. This development took place irrespective of sex. A trend toward a higher smoking prevalence among boys than among girls at $\mathrm{T} 1\left(\chi^{2}=3.2, \mathrm{df}=1 ; 0.05<\right.$ $\mathrm{p}<0.10)$ was also present at T2 $\left(\chi^{2}=3.3\right.$, $\mathrm{df}=1 ; 0.05<\mathrm{p}<0.10)$. The average (SD) number of cigarettes smoked per day increased from $\mathrm{T} 1$ to $\mathrm{T} 2(\mathrm{t}=8.24$, df $=266$; $\mathrm{p}<0.0001)$. Boys had a greater daily cigarette consumption compared with girls at T1 $(\mathrm{t}=2.90 ; \mathrm{df}=264 ; \mathrm{p}<0.005)$ and at $\mathrm{T} 2$ $(t=2.27, \mathrm{df}=264 ; \mathrm{p}<0.05)$ (table 1$)$.

TRENDS IN NUMBER OF SMOKERS $1987-1990$ (STUDIES $1 \& 2$ )

The populations of studies 1 and 2 were similar with respect to the social background variables cited above.

Table 1 Prevalence (\%) of experimental and regular smoking, and daily cigarette consumption, by sex, at one month before school transition (T1), four months after (T2), and among a different sample of pupils at the same schools measured three years later (T3)

\begin{tabular}{|c|c|c|c|c|c|}
\hline Time & Factor & Boys & Girls & Overall & $\mathrm{p}$ \\
\hline $\mathrm{T} 1$ & $\begin{array}{l}\text { have tried smoking } \\
\text { regular smoking } \\
\text { average daily cigarette consumption (SD) }\end{array}$ & $\begin{array}{l}76.6 \\
58.4 \\
8.0(5.7)\end{array}$ & $\begin{array}{l}78.9 \\
50.7 \\
7.0(4.6)\end{array}$ & $\begin{array}{l}77.6 \\
54.6 \\
7.7(5.3)\end{array}$ & $\begin{aligned} \mathrm{NS} \\
0.05<\mathrm{p}<0.010 \\
\mathrm{p}<0.005\end{aligned}$ \\
\hline $\mathrm{T} 2$ & $\begin{array}{l}\text { regular smoking } \\
\text { average daily cigarette consumption (SD) }\end{array}$ & $\begin{array}{l}63.6 \\
11.7(5.4)\end{array}$ & $\begin{array}{l}56.0 \\
10.2(5.4)\end{array}$ & $\begin{array}{l}59.9 \\
10.8(5.6)\end{array}$ & $\begin{array}{c}0.05<\mathrm{p}<0.10 \\
\mathrm{p}<0.05\end{array}$ \\
\hline T3 & $\begin{array}{l}\text { have tried smoking } \\
\text { regular smoking } \\
\text { average daily cigarette consumption (SD) }\end{array}$ & $\begin{array}{l}82.7 \\
49.4 \\
15.5(5.9)\end{array}$ & $\begin{array}{l}83.6 \\
49.0 \\
14.5(5.0)\end{array}$ & $\begin{array}{l}83.2 \\
49.1 \\
14.9(5.5)\end{array}$ & $\begin{array}{l}\text { NS } \\
\text { NS } \\
\text { NS }\end{array}$ \\
\hline
\end{tabular}

The percentage of pupils with daily cigarette use was different between $T 1$ and $T 2(p<0.001)$ and between $T 2$ and $T 3$ $(\mathrm{p}<0.005)$. The average daily cigarette consumption was different between $\mathrm{T} 1$ and $\mathrm{T} 2(\mathrm{p}<0.0001)$ and between $\mathrm{T} 2$ and $\mathrm{T} 3$ 
Table 2 Knowledge of the health hazards of smoking in 283 male and 272 female boarding school pupils (\%) (study 1)

\begin{tabular}{|c|c|c|c|c|}
\hline Question & Yes & Maybe & Don't know & No \\
\hline $\begin{array}{l}\text { Can smoking cause cancer } \\
\text { of the lungs? }\end{array}$ & 46.5 & 49.0 & 3.8 & 0.7 \\
\hline $\begin{array}{l}\text { Is lung cancer a deadly } \\
\text { disease? }\end{array}$ & 92.3 & 5.1 & 2.0 & 0.6 \\
\hline $\begin{array}{l}\text { Can smoking cause disease } \\
\text { of the lungs? }\end{array}$ & 93.8 & 5.5 & 0.4 & 0.4 \\
\hline Can lung disease be deadly? & 73.0 & 22.3 & 4.4 & 0.4 \\
\hline $\begin{array}{l}\text { Is tobacco cough a sign of } \\
\text { damage to the lungs? }\end{array}$ & 61.6 & 25.1 & 11.5 & 1.8 \\
\hline $\begin{array}{l}\text { Can smoking cause } \\
\text { heart disease? }\end{array}$ & 49.3 & 25.1 & 22.7 & 2.9 \\
\hline 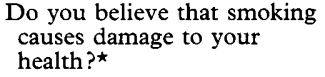 & 78.1 & 16.8 & 4.0 & 1.1 \\
\hline
\end{tabular}

* Girls were more likely than boys to answer "yes" to this question $(\mathrm{p}<0.001)$

In study 2 the percentage of pupils with regular cigarette use was $49.1 \%$ and the average daily cigarette consumption (SD) was 14.9 (5.5). The percentage of smokers in study 2 was lower than study $1\left(\chi^{2}=13.4 ; \mathrm{f}=1\right.$; $\mathrm{p}<0.005)$ but the average daily consumption was higher $(\mathrm{t}=4.1, \mathrm{df}=479 ; \mathrm{p}<0.001)$ (table 1).

\section{KNOWLEDGE CONCERNING THE HEALTH HAZARDS OF SMOKING}

An estimation of the pupils' knowledge about the health hazards of smoking from study 1 is presented in table 2 . Two of the 557 participants were excluded from these analyses because of conflicting information. Generally students had some knowledge about diseases caused by tobacco smoking, but only $46.5 \%$ were certain that smoking causes lung cancer and only $49.3 \%$ were certain that heart disease may be caused by smoking. By contrast, $93.8 \%$ were certain that smoking causes lung disease. Beliefs about the kind and severity of illnesses caused by smoking were similar among boys and girls, except that girls were more likely than boys to believe that smoking may cause damage to one's personal health $\left(\chi^{2}=17.3\right.$, $\mathrm{df}=3 ; \mathrm{p}<0.001)$.

DESIRES TO QUIT

Among smokers in study $2,70 \%$ had a desire to quit smoking. These smokers cited the following reasons for their desire to quit: health hazards $(59.6 \%)$, costs $(74.9 \%)$, consideration of other persons $(35.7 \%)$, better fitness $(58.9 \%)$, and better appearance $(20.3 \%)$ (table 3$)$.

\section{CONTROL ANALYSES}

The results of the control study showed a similar percentage of pupils with regular cigarette usage and a similar daily cigarette consumption to study 2 .

\section{Discussion}

The present study investigated smoking behaviour among 14- to 17-year-old boarding-
Table 3 Desires to quit smoking among 360 smoking boarding school pupils (\%) (study 2)

\begin{tabular}{|c|c|c|c|c|}
\hline & $\begin{array}{l}\text { Very } \\
\text { much }\end{array}$ & $\begin{array}{l}\text { To some } \\
\text { extent }\end{array}$ & Maybe & No \\
\hline Wishes to quit smoking ${ }^{\star}$ & 34.7 & 35.6 & 18.3 & 11.4 \\
\hline $\begin{array}{l}\text { Wishes to quit because of } \\
\text { health hazards } \star \star\end{array}$ & 39 & 19.8 & 173 & 23.1 \\
\hline $\begin{array}{l}\text { Wishes to quit because of } \\
\text { economics }\end{array}$ & 50.7 & 24.2 & 9.7 & 15.4 \\
\hline $\begin{array}{l}\text { Wishes to quit in consider- } \\
\text { ation of others } \star \star\end{array}$ & 13.5 & 22.2 & 26.1 & 38.2 \\
\hline $\begin{array}{l}\text { Wishes to quit because of } \\
\text { fitness } \star \star\end{array}$ & 45.1 & 23.8 & 14.6 & 16.5 \\
\hline $\begin{array}{l}\text { Wishes to quit because of } \\
\text { appearance } \star\end{array}$ & 11.6 & 8.7 & 13.8 & 65.8 \\
\hline
\end{tabular}

* Denominator was all smokers.

$\star \star$ Denominator was smokers who wanted to quit smoking "very much" or "to some extent".

school pupils. Almost all smokers reported increased cigarette use after school transition. The information obtained retrospectively about previous cigarette consumption may have been imprecise; however, the time period between the survey (T2) and the pre-transition time (T1) was rather short. Because smoking is allowed in Danish schools and because the anonymity of the pupils was secured, they had no reason to give incorrect information. Other reports have shown a good reliability of selfadministered questionnaires concerning smoking behaviour in adults ${ }^{7}$ and children ${ }^{8}$ and our control survey of cigarette consumption supported the validity of the information. The results seem representative for boarding school pupils because high prevalences of smokers were found in all schools and in two different generations of pupils.

Sixty percent of pupils in study 1 and $50 \%$ in study 2 were regular cigarette smokers. These are much higher proportions than the $20 \%$ reported among pupils in the same age group attending ordinary public schools. ${ }^{2-4,9}$ The designs of the studies concerning smoking behaviour in ordinary public schools were similar to that of our study. Among ordinary public school pupils the prevalence of smokers increased with age, but was lower for all age groups compared with the boarding school pupils. Girls in ordinary public schools had a higher prevalence of smokers than boys. ${ }^{2}$ In the boarding schools, however, the prevalence of smokers was independent of age and boys tended to have a higher prevalence than girls. This may indicate that boarding school pupils have different smoking patterns and motives to smoke than others.

Most of the pupils were smokers before school transition. The change of milieu, therefore, had little influence on smoking prevalence, although some started to smoke at the boarding schools, and among those who smoked at school transition, the daily cigarette consumption increased after school transition. Children who smoke often are more rebellious, extrovert, and socially engaged than nonsmokers of similar age. ${ }^{10,11}$ One study ${ }^{12}$ found that youngsters at boarding schools may have these characteristics in excess compared to their counterparts in ordinary public schools. This might at least to some degree explain the 
great number of regular smokers in the boarding schools. A significant imbalance in the recruitment of pupils to boarding schools among the social layers of the society has not been found. ${ }^{12}$ Boarding school pupils represent about $10 \%$ of Danish 14- to 17 -year-olds ${ }^{13}$ and they have never been included in Danish surveys addressing smoking prevalence among teenagers. Overlooking this large group might result in underestimates of the prevalence of smokers.

Although a decrease in the prevalence of smokers was seen during the three-year period between surveys, $50 \%$ of the pupils were still smokers in 1989/90. This unsatisfactory result calls for an intensification of smoking prevention measures for this group. This is especially important as the daily cigarette consumption was higher in $1989 / 90$, which implies a greater risk for the development of smoking-related disabilities.

Because of the similarity of data concerning knowledge of smoking-induced health hazards between study 1 and earlier reports ${ }^{14}$ and because we did not expect any change in this knowledge over a short time interval, the pupils' knowledge of smoking-provoked diseases was only surveyed in study 1. Pupils' knowledge concerning tobacco-associated diseases was generally unsatisfactorily low. This is in accordance with earlier reports, ${ }^{14}$ and implies that education about the influence of smoking on health must be strengthened.

Smokers' desires to quit smoking were only surveyed in study 2 as the need for this survey arose from the somewhat unexpected, high prevalence of smokers found in study 1 . Efficient smoking cessation programmes should be carried out in boarding schools as the majority of the smoking children wanted to quit. The reasons for their desire to quit may suggest the appropriate content for a programme, but the development of an effective programme also requires insight into the reasons why some pupils become smokers.
Considering the great health risk of young smokers, studies aimed at uncovering factors responsible for initiation of smoking and conditions that promote the continuation of smoking in youngsters are needed.

A specific group of youngsters with a high prevalence of smokers was identified in the present study. Other specific groups of children with similar smoking problems may exist. We recommend research to identify and psychosocially characterise such groups. Antismoking measures could be more successful if they were aimed at these groups.

1 Fielding JE. Smoking: health effects and control. $N$ Engl $\mathfrak{f}$ Med 1985; 313: 4917-20.

2 Ibsen KK. Smoking and attitudes to smoking among Danish school children in 1985. Ugeskr Lager 1986;148: 2714-5.

3 Holstein BE, Ito H, Due P. Smoking among children aged 11-15 years in Denmark in 1988. Ugeskr Lager 1990; 152: 2651-4.

4 Ito H, Holstein BE, Ibsen KK. School children's smoking behaviour and attitude. A sociological perspective. Ugeskr Lager 1987; 149: 396-400.

5 Jensen EJ, Overgaard E. Investigation of smoking habits among 14-17-year-old boarding school pupils: factors which influence smoking status. Public Health 1993; 107: 117-23.

6 Dixon WJ (ed). BMDP statistical software. Los Angeles: University of California Press, 1985.

7 Petitti DB, Friedman GD, Kahn W. Accuracy of information on smoking habits provided on selfadministered research questionnaires. Am $\mathcal{f}$ Public Health 1981; 71: 308-11.

8 McKennel AG. Bias in the reported incidence of smoking reported by children. Int $\mathcal{f}$ Epidemiol $1980 ; 9$ : 167-77.

9 Nielsen PE, Zacho J, Olsen JA, Olsen CA. Alterations in the Danes' smoking habits in the period 1970-87. Ugeskr Leeger 1988; 150: 2229-33.

10 Murray M, Swan AV, Vewley BR, Johnson MRD. The development of smoking during adolescence - the MRC/Derbyshire study. Int $\mathcal{f}$ Epidemiol 1983; 12 : 185-91.

11 Hansen WB, Collins LM, Johnson CA, Gramham JW Self-initiated smoking cessation among high school students. Addict Behav 1985; 10: 265-71.

12 Balle T, Nielsen SB. Investigation of performance in boarding school pupils. Expectations and experience. Holstebro, Denmark: The free boarding schools, 1982, pp 27-40.

13 The Danish Secretary Office of Culture, Department of Budgets. Budget analysis for free boarding schools. Copen-

hagen, 1990, pp 35-6.
14 Ibsen KK, Juel K. Smoking. A nationwide investigation among 3,500 young people in senior schools and during the first year of technical colleges. Ugeskr Leger 1984; 146: 3055-7. 